\title{
A computational study of cysteine and glutathione binding to small gold cluster $\mathrm{Au}_{8}$
}

\author{
Nguyen Thanh $\mathrm{Si}^{1}$, Pham Vu Nhat ${ }^{2}$
}

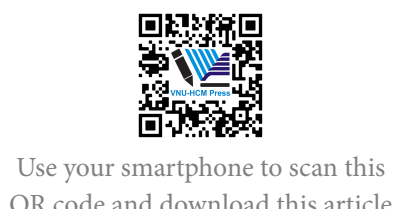

QR code and download this article
${ }^{1}$ Computational Chemistry Research Group, Ton Duc Thang University, Ho Chi Minh City, Viet Nam

${ }^{2}$ Department of Chemistry, Can Tho University, Viet Nam

\section{Correspondence}

Nguyen Thanh Si, Computational Chemistry Research Group, Ton Duc Thang University, Ho Chi Minh City, Viet Nam

History

- Received: 2019-10-07

- Accepted: 2019-12-10

- Published: 2020-02-17

DOI : 10.32508/stdj.v23i1.1715

\section{Check for updates}

\section{Copyright}

(c) VNU-HCM Press. This is an openaccess article distributed under the terms of the Creative Commons Attribution 4.0 International license.

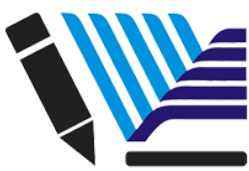

VNU-HCM Press

\begin{abstract}
Introduction: Understanding the binding mechanism between gold nanoparticles and biomolecules is a fundamental step for numerous applications in biosensors and targeted drug delivery. This study aims to clarify the adsorption behaviors of CYS and GSH on the gold surface using a small gold $\mathrm{Au}_{8}$ cluster as a model reactant. Methods: Here, we examine in details the molecular interaction between $\mathrm{Au}_{8}$ cluster with cysteine (CYS) and glutathione (GSH) by means of density functional theory (DFT). The PBE functional is employed in combination with the cc-pVTZ basis set for non-metal atoms and the cc-pVTZ-PP basis set for gold. Harmonic vibrational frequencies are also computed to confirm optimized geometries as local minima or transition states on the potential energy surfaces. Results: The calculated results show that these molecules prefer to anchor on the gold cluster via the sulfur atom with the adsorption energies of 20.3 and $30.8 \mathrm{kcal} / \mathrm{mol}$ for CYS and GSH, respectively, in gas phase. In water, such values are considerably reduced, namely $19.0 \mathrm{kcal} / \mathrm{mol}$ for CYS and $26.4 \mathrm{kcal} / \mathrm{mol}$ for GSH. If a visible light with a frequency of $v=6 \times 10^{14} \mathrm{~Hz}$ $(500 \mathrm{~nm})$ is applied, the time for the recovery of CYS and GSH from the most stable complexes will be about 1.24 and $6.03 \times 10^{7}$ seconds at $298 \mathrm{~K}$ in gas phase. Conclusion: The Aus cluster could be a promising material for designing sensor in CYS and GSH selective detection.

Key words: Au8 cluster, cysteine, density functional theory, glutathione
\end{abstract}

\section{INTRODUCTION}

In the past decades, gold clusters have been the subject of various studies owing to their potential applications in biosensors ${ }^{1,2}$, catalysis ${ }^{3}$, biomedical dignostics $^{4,5}$, organic synthesis ${ }^{6,7}$, environment ${ }^{4}$, drug delivery systems ${ }^{8}$, analysis ${ }^{9}$, electrochemistry ${ }^{10,11}$. Recently, relevant studies have been carried out to elucidate the nature of interactions between biomolecules including amino acids, peptides, DNA constituents and small gold clusters, using both experimental and theoretical techniques.

According to Xie et al. ${ }^{12}$, the interaction between gold cluster $\mathrm{Au}_{n}(n=3,4)$ with cysteine and glycine is stabilized mainly due to $\mathrm{Au}-\mathrm{NH}_{2}$ bond via the transfer of charge from the amine group to the $\mathrm{Au}$ atom. In another investigation on cysteine and larger gold $\mathrm{Au}_{n}$ cluster $(n=8,10 \text { and } 12)^{13}$, the resulting complexes were found to be stabilized due to the strong $\mathrm{Au}-\mathrm{S}$ bonding. Interactions of proline amino acid with $\mathrm{Au}_{3}$ cluster was also examined by DFT calculations ${ }^{14}$. Accordingly, two factors, i.e. the anchoring $\mathrm{N}-\mathrm{Au}, \mathrm{O}-\mathrm{Au}$ bonds and the non-conventional O-H... Au hydrogen bond, dominate the interactions. Other striking finding is that gold clusters prefer to anchor on the terminal amide group ${ }^{13-15}$.
In a study of $\mathrm{M}_{3}$ clusters $(\mathrm{M}=\mathrm{Ag}, \mathrm{Au}$ and $\mathrm{Cu})$ binding to histidine in both neutral and anionic states, Javan et al. ${ }^{16}$ found that the metal clusters tend to oxidize histidine by getting electron from the lone pair orbitals of N, O, S atoms, and form highly stable anchor bonds. Scanning tunneling microscopy was also employed to probe the cysteine deposited on the $\mathrm{Au}(111)$ surface ${ }^{17}$. Novel network-like cluster structures of the layers with six and three cystine molecules on the $\mathrm{Au}$ surface have been found. A molecular dynamics simulation study of the adsorption mechanism of twenty amino acids and four surfactants on $\mathrm{Au}(111)$ in aqueous solution predicted an absorption energy around $3-26 \mathrm{kcal} / \mathrm{mol}^{18}$. The adsorption strength were found to correlate well with the degree of coordination of polarizable atoms $(\mathrm{O}, \mathrm{N}, \mathrm{C})$ and determined by the molecular size/shape.

Cysteine and glutathione are among the most important thiol-containing compounds due to their special role in many biochemical reactions ${ }^{19}$. Cysteine (CYS) has many important cellular functions and its presence in biological fluids such as human plasma and urine is essential for clinical diagnostics of several diseases. The molecule on a solid surface is an important issue for either protein study or differentiating amino acids ${ }^{19}$. Previous study of cysteine adsorption 
on $\mathrm{Au}(100)$ showed the tendency of flat adsorption geometries due to the thiolate-amino bonds ${ }^{20}$.

Glutathione (GSH) or tripeptide $\gamma$-L-glutamyl-Lcysteinyl-glycine is well-known for its function in protecting the blood red cells from oxidative damage and maintaining the standard reduced state of the cells. In addition, the molecule is an integral part in the detoxification of the cells, responsible for elimination of harmful organic peroxides and free radicals. Accordingly, it absorbs toxins including pesticides, solvents, and heavy metals, then converting them into forms that are able to be excreted in urine or bile ${ }^{19}$. Moreover, its anionic form exhibits the particularly high tendencies to interact with gold clusters $^{21}$. Recently, Thomas and co-workers ${ }^{22}$ introduced a novel approach for selective detection of cysteine and glutathione in many biological systems using gold nanorods.

Despite numerous efforts devoted to the absorption of such thiol-containing compounds on $\mathrm{Au}_{N}$ systems, the interaction mechanism is still not fully understood. Additionally, most of previous studies were performed in vacuum, while the effects of solvents have not been taken accounts. Understanding the interaction mechanism of gold nanoparticles with biomolecules is a fundamental step in designing and development of tiny biosensors.

This theoretical study aims to elucidate the adsorption behaviors of two thiol-containing cysteine and glutathione on the gold surface using small gold $\mathrm{Au}_{8}$ cluster as a model reactant. Current results could provide us with fundamental insights into the functionalization of gold nanoclusters with biomolecules and envisage their applicability in bio-chemical sensing and detection.

\section{COMPUTIONAL METHODS}

All calculations were performed with the aids of the Gaussian 09 program $^{23}$. The geometries were fully optimized, making use of the functional PBE in conjunction with the basis sets cc-pVTZ-PP ${ }^{24}$ for gold and cc-pVTZ for non-metals.

Initial structures of the $\mathrm{Au}_{8} \bullet \mathrm{CYS}$ and $\mathrm{Au}_{8} \bullet \mathrm{GSH}$ complexes for geometry optimizations were created by attaching biomolecules via electron-rich centers, i.e. the $\mathrm{S}, \mathrm{N}$ and $\mathrm{O}$ atoms, to the lowest-energy form of $\mathrm{Au}_{8}$. Harmonic vibrational frequencies were also computed to verify that optimized geometries are true local minima and to estimate the zero-point vibrational energy (ZPE) corrections. Zero-point and thermal enthalpies corrections were then employed to predict free energies via the Equation (1).

$\triangle G^{o}(298 K)=\triangle E+\triangle Z P E+\triangle T C G$ where $\Delta \mathrm{E}$ is the relative electronic energy at $0 \mathrm{~K} ; \Delta \mathrm{ZPE}$ is the relative vibrational energy at $0 \mathrm{~K} ; \Delta \mathrm{TCG}$ is relative changes in Gibbs free energy going from 0 to 298 $\mathrm{K}$. The complextion energy $\mathrm{E}_{c}$ of the interaction between $\mathrm{Au}_{8}$ cluster and CYS/GSH was computed as the value of energy difference:

$$
E_{c}=E_{A u_{8} . C Y S / G S H}-\left(E_{A u_{8}}+E_{C Y S / G S H}\right)
$$

where $\mathrm{E}_{X}$ is the lowest electronic energy of the $\mathrm{X}$ species. Hence, a negative value of $E_{c}$ indicates a favorable adsorption. The greater the computed value of the complexation energy, the stronger is the affinity of cysteine binding to the gold cluster. The effect of solvent (water) was simulated using the default model IEF-PCM (Integral Equation Formalism-Polarizable Continuum Model) ${ }^{25}$ provided by Gaussian.

For deeper insights into the effect of interacting species on each other, the electronic properties such as the HOMO-LUMO energy gap $\left(\mathrm{E}_{g}\right)$ and the density of states (DOS) were examined. The $\mathrm{E}_{g}$ is a suitable aspect for defining the kinetic reactivity of materials $^{26}$, and its conversion upon the adsorption process reflects the sensitivity of an adsorbent to an adsorbate. The GaussSum program ${ }^{27}$ has been used for DOS calculations.

\section{RESULTS - DISCUSSION}

\section{Structural optimization}

As expected, $\mathrm{Au}_{8}$ cluster prefers to interact with CYS or GSH species through electron-rich atoms, i.e. S, N and $\mathrm{O}$ atoms. These atoms with lone pair are more willing to form bonding with the $5 d$ and $6 s$ orbitals of the Au atom. At the PBE/cc-pVTZ/cc-PVTZ-PP level of theory, we located four conformations for $\mathrm{Au}_{8} \times \mathrm{CYS}$ complexes, denoted as C1-C4 (Figure 1), while for $\mathrm{Au}_{8} \times \mathrm{GSH}$ complexes, eight isomers G1-G8 (Figure 2) have been obtained. Noticeably, the geometries of both CYS, GSH and Aus cluster are almost unmodified during the complexation. In addition, these structures have positive harmonic frequencies, indicating that they are local minima on the potential energy surfaces. The calculated complexation energies and bond lengths of the resulting complexes are listed in Table 1.

The most stable conformation of $\mathrm{Au}_{8} \bullet \mathrm{CYS}$ complex, i.e. $\mathbf{C 1}$ form in Fig. 1, is formed by anchoring the thiol group on the low-coordinated gold atom of the $\mathrm{Au}_{8}$ ring. This can be understood by the hard-soft acid-base (HSAB) theory ${ }^{28}$, as the softer sulfur element is more willing to form strong bonds with soft elements like gold than the harder nitrogen and oxygen elements. In the $\mathbf{C} \mathbf{1}$ complex, the Au-S bond length 


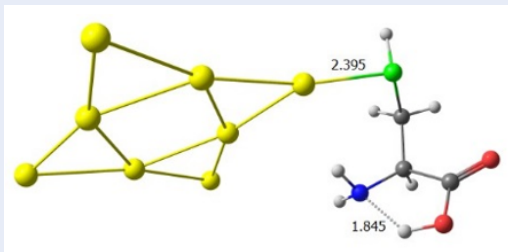

C1 (0.00)

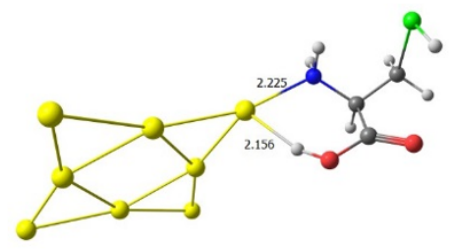

C3 (2.40)

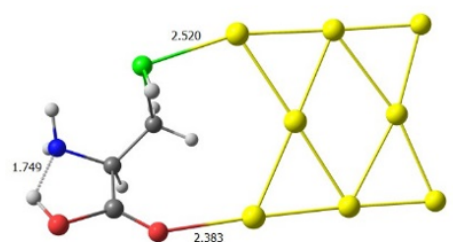

C2 (1.77)

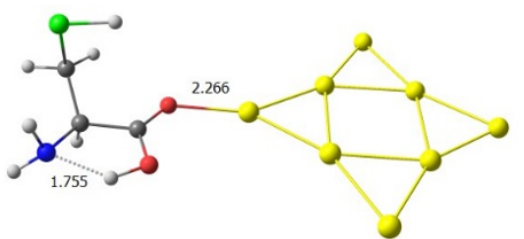

C4 (6.21)

Figure 1: Optimal structures located for the $\mathrm{Au}_{8} \bullet \mathbf{C Y S c o m p l e x}$ in gas-phase (C1-C4). The relative values $(\mathrm{kcal} / \mathrm{mol})$ to the lowest-energy $\mathrm{C} 1$ conformation are given in brackets

Table 1: Complexation energy ( $\left.\mathrm{E}_{c}, \mathbf{k c a l} / \mathrm{mol}\right)$, Au-Y bond length $\left(r_{A u-Y}, \stackrel{\circ}{A}\right)$ of the $\mathbf{A u}_{8} . \mathrm{CYS}$ complexes (C1-C4) at the same PBE/cc-pVTZ/cc-pVTZ-PP level of theory

\begin{tabular}{lccc} 
Conformation & Ec & Bond & \\
$\mathrm{C} 1$ & -20.27 & $\mathrm{Au}-$ & 2.395 \\
$\mathrm{C} 2$ & -18.50 & $\mathrm{Au}-$ & 2.520 \\
& & $\mathrm{Au}-\mathrm{O}$ & 2.383 \\
$\mathrm{C} 3$ & -17.87 & $\mathrm{Au}-$ & 2.225 \\
& & $\mathrm{Au}-\mathrm{H}$ & 2.156 \\
$\mathrm{C} 4$ & -14.06 & $\mathrm{Au}-\mathrm{O}$ & 2.266 \\
\hline
\end{tabular}

is $2.395 \AA$, which is slightly longer than the sum of covalent radii of $\mathrm{Au}(1.35 \AA)$ and $\mathrm{S}(1.02 \AA)$ atoms. Previous study also predicted that $\mathrm{Au}$ atom exhibits a higher affinity with $\mathrm{S}$ atom ${ }^{29}$.

The second most stable species C2, which is constructed by binding $\mathrm{Au}_{8}$ to the thiol and carbonyl groups of CYS is only about $\sim 2 \mathrm{kcal} / \mathrm{mol}$ higher in energy than the $\mathbf{C l}$ conformation. The Au-S and Au-O distances in $\mathbf{C} 1$ are 2.520 and $2.383 \AA$, respectively, which are quite larger than the sum of covalent radii of Au-S (2.370 $\AA$ ) and Au-O (2.080 A) bonds. The remaining conformations including $\mathbf{C} 3$ and $\mathbf{C} 4$ conformation are the most unstable conformations. In these conformations, they are formed by anchoring $\mathrm{Au}$ atom on CYS through $\mathrm{N}$ and $\mathrm{O}$ atoms, having stronger basicity than $\mathrm{S}$ atom. The second element is that their associated lengths are larger than the total of theirs covalent radii are 2.100 and $2.080 \AA$, respectively.
For the interaction between $\mathrm{Au}_{8}$ cluster and $\mathrm{GSH}$ molecules, eight conformations, i.e. G1-G8 in Figure 2, have been located. Among these, the most stable structure $\mathrm{G} 1$ is formed by anchoring the $\mathrm{Au}_{8}$ moiety on the $\mathrm{S}$ and $\mathrm{O}$ atoms of the thiol and carbonyl group. The $\mathrm{Au}$ atom has strong affinity with $\mathrm{S}$ atom, but the formation of inter-molecular hydrogen bonds (H-bonds) in GSH is also a vital factor that significantly contributes to stabilizing the $\mathrm{Au}_{8}$.GSH complex $^{21}$. In fact, in the $\mathbf{G} \mathbf{1}$ conformer, the calculated result obtain three $\mathrm{H}$-bonds, namely $\mathrm{N}-\mathrm{H} \cdots \mathrm{O}=\mathrm{C}$, S$\mathrm{H} \cdots \mathrm{O}=\mathrm{C}$ and $\mathrm{COOH} \cdots \mathrm{NH}_{2}$ bonds. The $\mathrm{H}$-bonds in G1 are much shorter than those of other products.

The next isomer $\mathbf{G} 2$ is only about $\sim 3 \mathrm{kcal} / \mathrm{mol}$ less stable than the ground-state form G1. In G2, the $\mathrm{Au}$ atom links with cystenyl (Au-S) and glutamyl (Au$\mathrm{O})$, increasing the internal H-bonds in GSH. The remaining conformations (G3-G8) are quite unstable, being around $10-19 \mathrm{kcal} / \mathrm{mol}$ above the most stable form G1. In G3-G8 complexes, the gold cluster bind- 


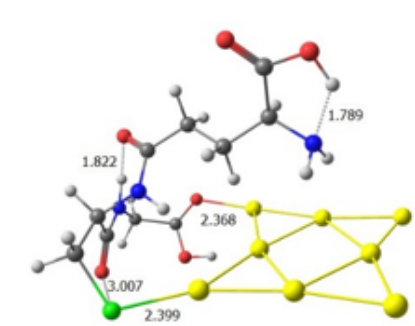

G1 (0.00)

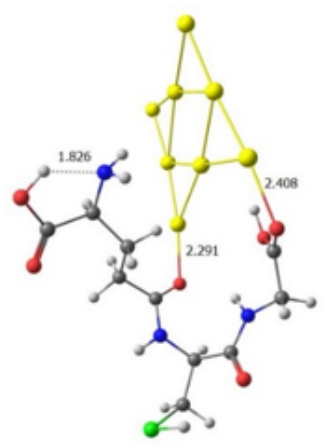

G3 (10.07)

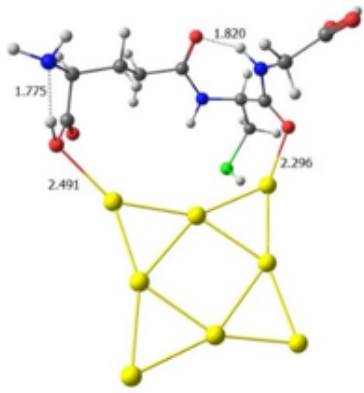

G5 (16.38)

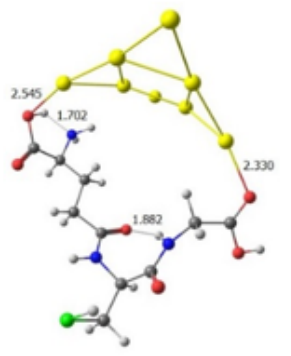

G7 (17.82)

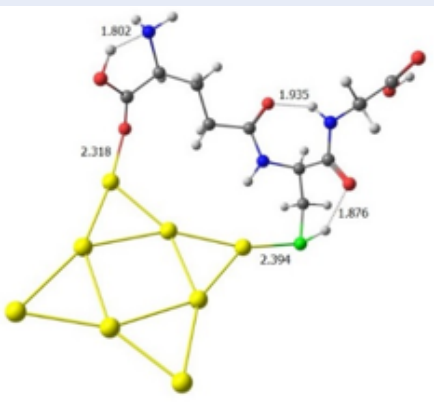

G2 (2.76)

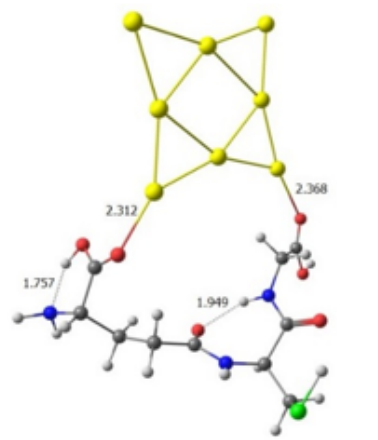

G4 (13.43)

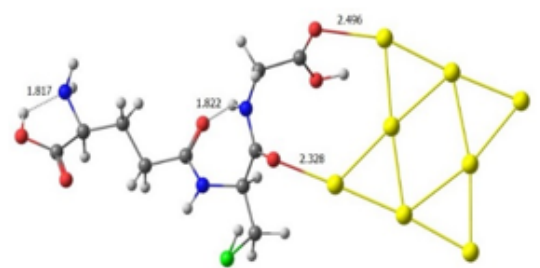

G6 (16.81)

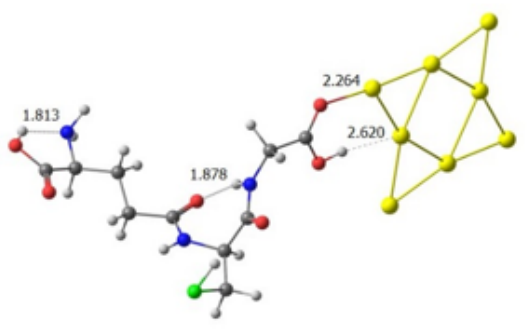

G8 (18.74)

Figure 2: Optimal structures located for the $\mathrm{Au}_{8} \bullet \mathrm{GSH}$ complex in gas-phase (G1-G8). The relative values $(\mathrm{kcal} / \mathrm{mol})$ to the lowest-energy $\mathrm{G} 1$ conformation are given in brackets. 
Table 2: Complexation energy ( $\left.E_{c}, \mathbf{k c a l} / \mathbf{m o l}\right), A u-Y$ bond length $\left(r_{A \mu-Y}, \AA\right)$ of the $A u_{8} . G S H$ complexes $(\mathbf{G} 1-\mathbf{G 8})$ at the same PBE/cc-pVTZ/cc-pVTZ-PP level of theory

\begin{tabular}{|c|c|c|c|}
\hline Conformation & Ec & Bond & $r_{A u-Y}$ \\
\hline \multirow[t]{2}{*}{ G1 } & -30.75 & $\mathrm{Au}-$ & 2.399 \\
\hline & & $\mathrm{Au}-\mathrm{O}$ & 2.368 \\
\hline \multirow[t]{2}{*}{ G2 } & -27.99 & $\mathrm{Au}-$ & 2.394 \\
\hline & & $\mathrm{Au}-\mathrm{O}$ & 2.318 \\
\hline \multirow[t]{2}{*}{ G3 } & -20.68 & $\mathrm{Au}-\mathrm{O}$ & 2.291 \\
\hline & & $\mathrm{Au}-\mathrm{O}$ & 2.408 \\
\hline \multirow[t]{2}{*}{ G4 } & -17.32 & $\mathrm{Au}-\mathrm{O}$ & 2.312 \\
\hline & & $\mathrm{Au}-\mathrm{O}$ & 2.368 \\
\hline \multirow[t]{2}{*}{ G5 } & -14.37 & $\mathrm{Au}-\mathrm{O}$ & 2.491 \\
\hline & & $\mathrm{Au}-\mathrm{O}$ & 2.296 \\
\hline \multirow[t]{2}{*}{ G6 } & -13.94 & $\mathrm{Au}-\mathrm{O}$ & 2.328 \\
\hline & & $\mathrm{Au}-\mathrm{O}$ & 2.496 \\
\hline \multirow[t]{2}{*}{ G7 } & -12.93 & $\mathrm{Au}-\mathrm{O}$ & 2.545 \\
\hline & & $\mathrm{Au}-\mathrm{O}$ & 2.330 \\
\hline \multirow[t]{2}{*}{ G8 } & -12.01 & $\mathrm{Au}-\mathrm{O}$ & 2.264 \\
\hline & & $\mathrm{Au}-\mathrm{H}$ & 2.620 \\
\hline
\end{tabular}

ing to GSH molecule through the $\mathrm{O}$ atoms of carbonyl groups.

\section{Chemical re activity}

The quantum chemical descriptors of $\mathrm{Au}_{8}$ cluster, CYS and GSH molecules including chemical potential $\mu$, total hardness $\eta$ and electrophile index $\omega$ are also examined to evaluate the chemical reactivity of systems considered. The calculated results at the PBE/ccpVTZ/cc-pVTZ-PP level of theory are presented in Table 3.

As expected, the $\mathrm{Au}_{8}$ has a more negative chemical potential than CYS and GSH molecules. In addition, the cluster exhibits a much larger electrophile index than the biomolecules. This strongly supports for the view that the metals are more willing to act as an electron-acceptor, while both CYS and GSH tend to be an electron-donor. Such a charge transfer from the biomolecules to the gold atoms results in a significant change in the HOMO-LUMO energy gap $\left(\triangle \mathrm{E}_{g}\right)$, which is reported as follows:

$$
\triangle E_{g}=\frac{\left|E_{g_{2}}-E_{g_{1}}\right|}{E_{g_{1}}} \times 100 \%
$$

where $E_{g_{1}}$ and $E_{g_{2}}$ are the value of the $E_{g}$ for the bare $\mathrm{Au}_{8}$ cluster and the $\mathrm{Au}_{8} \bullet \mathrm{X}(\mathrm{X}=\mathrm{CYS}, \mathrm{GSH})$ complexes, respectively. This parameter can also be used to evaluate the sensitivity of the clusters to the presence of biomolecules.

As shown in the plot of DOS (Figure 3), the band gap of $\mathrm{Au}_{8}$ in $\mathbf{C 1}(1.64 \mathrm{eV})$ and $\mathbf{~} \mathbf{1}(1.69 \mathrm{eV})$ considerably increase by $17 \%$ and $21 \%$, respectively, as compared to that in the free $\mathrm{Au}_{8}(1.40 \mathrm{eV})$. In general, the HOMO energy of $\mathrm{Au}_{8}$ cluster is almost unchanged, while its LUMO energy substantially modified. In fact, due to an electron transfer from biomolecules to cluster, the LUMO of $\mathrm{Au}_{8}$ increased from $-4.35 \mathrm{eV}$ in free cluser to $-3.92 \mathrm{eV}$ and $-3.84 \mathrm{eV}$ in $\mathbf{C 1}$ and $\mathbf{G} \mathbf{1}$ complexes, respectively.

\section{Solvent effect and recovery time}

Let us recall that all calculations above are performed in gas phase. In practice, sensors are often used to detect substances in solution, i.e. water environment. Therefore, further calculations have been carried out to examine the effects of water solvent on the interactions, using the IEF-PCM model (Integral Equation Formalism-Polarizable Continuum Model). The computed results are summarized in Table 4.

In water, complexation energies, the changes of enthalpy and free energy become less negative, but also exhibit a similar trend as in gas phase. This is due to the fact that hydration energies of products are 
Table 3: Quantum chemical descriptors of $\mathrm{Au}_{8}$ cluster, $\mathrm{CYS}$ and GSH at the PBE/cc-pVTZ/cc-pVTZ-PP level of theory

\begin{tabular}{llllllll}
\hline Structures & $\mathrm{E}_{\text {Номо }}, \mathrm{eV}$ & $\mathrm{E}_{\text {LUMO }}, \mathrm{eV}$ & $\mu, \mathrm{eV}$ & $\eta, \mathrm{eV}$ & $\omega, \mathrm{eV}$ & $\mathrm{Eg}, \mathrm{eV}$ & $\triangle \mathrm{Eg}, \%$ \\
$\mathrm{Au} 8$ & -5.75 & -4.35 & -5.05 & 0.70 & 18.22 & 1.40 & - \\
$\mathrm{CYS}$ & -5.99 & -1.11 & -3.55 & 2.44 & 2.58 & 4.88 & - \\
$\mathrm{GSH}$ & -5.79 & -1.64 & -3.72 & 2.08 & 3.33 & 4.15 & - \\
$\mathrm{C} 1$ & -5.56 & -3.92 & -4.74 & 0.82 & 13.70 & 1.64 & 17.14 \\
$\mathrm{G} 1$ & -5.53 & -3.84 & -4.69 & 0.85 & 12.94 & 1.69 & 20.71 \\
\hline
\end{tabular}
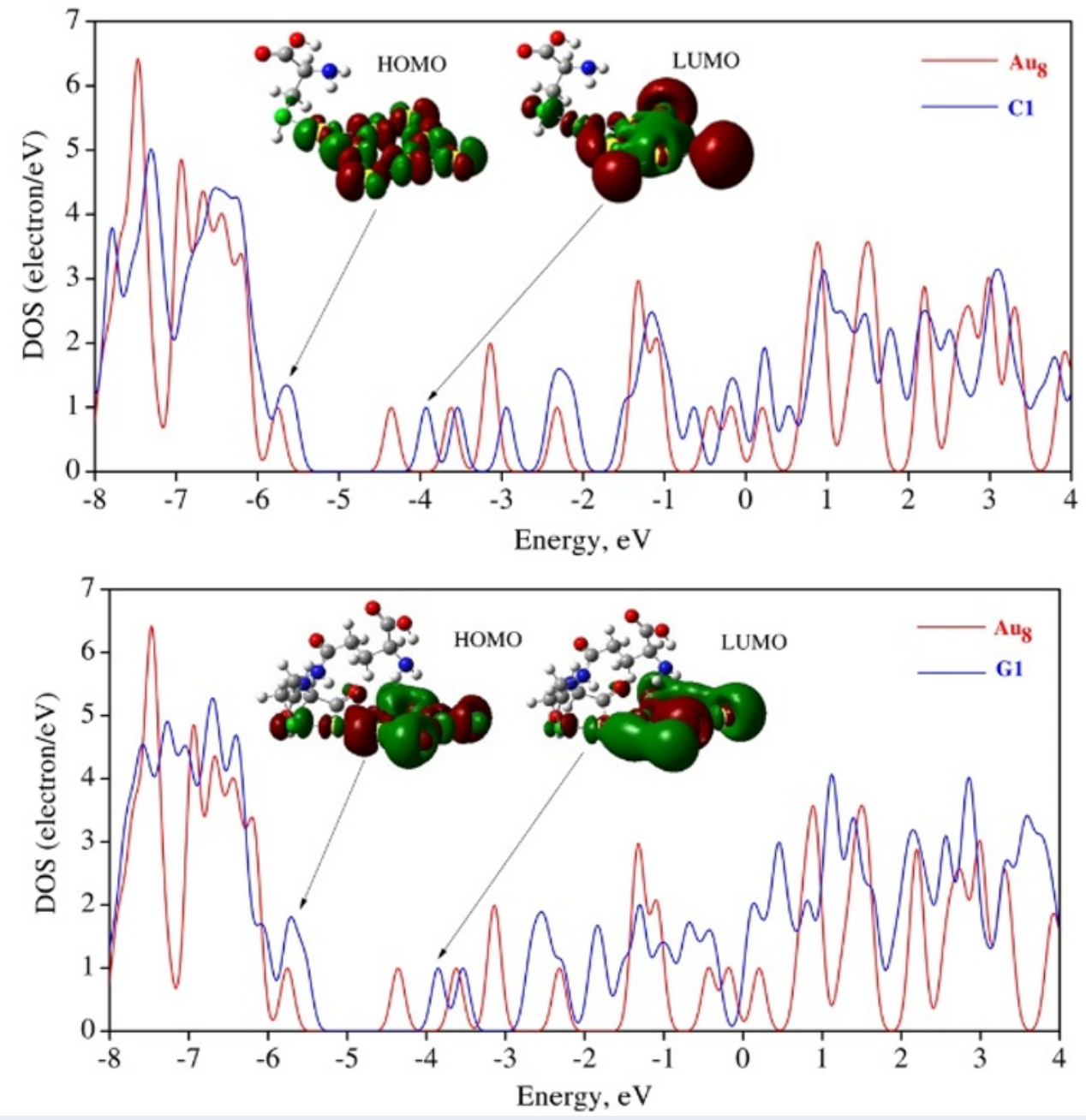

Figure 3: The DOS plot of C1 (top) và G1 (bottom) complexes. 
smaller than the sum of hydration energies of reactants. However, the interactions in water are still products favored with negative changes of free energies.

When exposed to the UV-Vis light, the biomolecules can undergo a desorption process. Very strong interactions are not favorable for chemical sensors because the desorption could be difficult and the sensor may suffer from long recovery times. According the transition state theory ${ }^{30}$, the recovery time ( $\tau$, seconds) exponentially depends on the binding energy $\mathrm{E}_{c}$ as follows:

$$
\tau=\left(v_{0}\right)^{-1} \cdot \exp \left(-E_{c} / \kappa_{B} T\right)
$$

where $\mathrm{T}$ is the temperature, $\kappa_{B}$ is the Boltzmann's constant, $v_{0}$ is the attempt frequency and $\kappa_{B} T=0.059$ $\mathrm{kcal} / \mathrm{mol}$ at $298 \mathrm{~K}$.

For the binding energy of $-20.27 \mathrm{kcal} / \mathrm{mol}$ in vacuum, the recovery of cysteine molecules from the $\mathrm{Au}_{8}$ surface at $298 \mathrm{~K}$ is in the range of 0.025 to 1.7 seconds (Table 5). In water, the recovery of the molecule from the $\mathrm{Au}_{8}$ surface turns out to be rather faster $\left(3 \times 10^{-2}\right.$ to $\left.2 \times 10^{-1} \mathrm{~s}\right)$. This indicates that the $\mathrm{Au}_{8}$ cluster could be a promising candidate for detection of cysteine, even at room temperature. Due to stronger interactions with $\mathrm{Au}_{8}$, the GSH molecules undergo much longer recovery times, namely from $1.2 \times 10^{6}$ to $8.4 \mathrm{x}$ $10^{7} \mathrm{~s}$ in gas phase and $8.2 \times 10^{2}$ to $5.7 \times 10^{4} \mathrm{~s}$ in water. Therefore, the $\mathrm{Au}_{8}$ cluster can be used to design tiny reusable sensors for selective detection of CYS and GSH molecules.

\section{CONCLUSION}

In this work, the structures, energetic properties and effects of water solution on the interaction of cysteine and glutathione molecules with the $\mathrm{Au}_{8}$ cluster was thoroughly examined by means of DFT calculations. The CYS and GSH moieties prefers to interact with the gold cluster through their thiol group. The nature of interactions is mainly determined by the charge transfer from the non-bonding pair of the sulfur atom to the empty orbitals of the gold cluster. Another noticable finding is that reactions of the gold cluster with these species are facile in nature, i.e. either molecular or dissociative chemisorptions are involved, rather than breaking molecular bonds and making again stronger bonds between the resulting fragments and the metals. The tendency to retain the initial forms of adsorbed molecules makes these clusters of great potential for applications in biochemical sensing and detection. If a visible light with a frequency of $v=6 \times 10^{14} \mathrm{~Hz}(500 \mathrm{~nm})$ is applied, the time for the recovery of CYS and GSH from the most stable complexes will be about 1.24 and $6.03 \times 10^{7}$ seconds at $298 \mathrm{~K}$ in gas phase. This indicates that $\mathrm{Au}_{8}$ cluster can be a promising candidate to develop tiny sensors in CYS and GSH selective detections.

\section{COMPETING INTERESTS}

The authors declare that there is no conflict of interest regarding the publication of this article.

\section{AUTHORS' CONTRIBUTIONS}

All the authors contribute equally to the paper including the research idea and written manuscript.

\section{ACKNOWLEDGMENT}

This research is funded by Vietnam National Foundation for Science and Technology Development (NAFOSTED) under grant number 103.01-2019.58. We are also grateful to the Interdisciplinary Center for Nano toxicity, Jackson State University, USA for using computing resources.

\section{REFERENCES}

1. Zeng S, Yong KT, Roy I, Dinh XQ, Yu X, Luan F. A review on functionalized gold nanoparticles for biosensing applications. Plasmonics. 2011;6(3):491-506. Available from: 10 . 1007/s11468-011-9228-1.

2. Zhang Y, Chu W, Foroushani AD, Wang H, Li D, Liu J. New gold nanostructures for sensor applications: A review. Materials (Basel). 2014;7(7):5169-201. PMID: 28788124. Available from: $10.3390 /$ ma7075169.

3. Xanthopoulou GG, Novikov VA, Knysh YA, Amosov AP. Nanocatalysts for low-temperature oxidation of CO: Review; 2015.

4. Mathew A, Pradeep T. Noble metal clusters: applications in energy, environment, and biology. Part Part Syst Charact. 2014;31(10):1017-53. Available from: 10.1002/ppsc. 201400033.

5. Bindhu MR, Umadevi M. Silver and gold nanoparticles for sensor and antibacterial applications. Spectrochim Acta A Mol Biomol Spectrosc. 2014;128:37-45. PMID: 24657466. Available from: 10.1016/j.saa.2014.02.119.

6. Su Y, Li X, Wang Y, Zhong H, Wang R. Gold nanoparticles supported by imidazolium-based porous organic polymers for nitroarene reduction. Dalton Trans. 2016;45(42):16896-903. PMID: 27711874. Available from: 10.1039/C6DT03050E.

7. Pina $C D$, Falletta $E$, Rossi M. Oxidation of allyl alcohol in the presence of a gold catalyst: a route to 3-hydroxypropionic acid. ChemSusChem. 2009;2(1):57-8. PMID: 19115300. Available from: 10.1002/cssc.200800172.

8. Ghosh P, Han G, De M, Kim CK, Rotello VM. Gold nanoparticles in delivery applications. Adv Drug Deliv Rev. 2008;60(11):1307-15. PMID: 18555555. Available from: 10. 1016/j.addr.2008.03.016.

9. Jin X, Jin X, Chen L, Jiang J, Shen G, Yu R. Piezoelectric immunosensor with gold nanoparticles enhanced competitive immunoreaction technique for quantification of aflatoxin B1. Biosens Bioelectron. 2009;24(8):2580-5. PMID: 19237278. Available from: 10.1016/j.bios.2009.01.014.

10. Suprun E, Shumyantseva V, Bulko T, Rachmetova S, Rad'ko S, Bodoev N. Au-nanoparticles as an electrochemical sensing platform for aptamer-thrombin interaction. Biosens Bioelectron. 2008;24(4):831-6. PMID: 18755579. Available from: 10.1016/j.bios.2008.07.008. 
Table 4: Effect of water solvents on the $\mathrm{C} 1$ and $\mathrm{G} 1$ conformations

\begin{tabular}{|c|c|c|c|c|c|c|}
\hline \multirow[t]{2}{*}{ Value } & \multicolumn{2}{|c|}{ Au8 } & \multicolumn{2}{|c|}{$\mathrm{C} 1$} & \multicolumn{2}{|c|}{ G1 } \\
\hline & Gas & Water & Gas & Water & Gas & Water \\
\hline $\mathrm{Ec}$ & - & - & -20.27 & -18.98 & -30.75 & -26.43 \\
\hline$\triangle \mathrm{H}$ & - & - & -19.15 & -17.20 & -30.77 & -25.94 \\
\hline$\triangle \mathrm{G}$ & - & - & -9.64 & -7.99 & -16.56 & -13.19 \\
\hline HOMO & -5.75 & -5.21 & -5.56 & -5.18 & -5.53 & -5.16 \\
\hline LUMO & -4.35 & -3.63 & -3.92 & -3.36 & -3.84 & -3.34 \\
\hline $\mathrm{Eg}$ & 1.40 & 1.58 & 1.64 & 1.82 & 1.69 & 1.82 \\
\hline$\% \triangle \mathrm{Eg}$ & - & - & 17.14 & 15.19 & 20.71 & 15.19 \\
\hline
\end{tabular}

Table 5: The time (in seconds) for the recovery of cys and gsh molecules from the $\mathrm{Au}_{8}$ surface at $298 \mathrm{~K}$

\begin{tabular}{llllr}
\hline$\lambda, \mathrm{nm}$ & & $\mathrm{C} 1$ & & $\mathrm{G} 1$ \\
& Gas & Water & Gas & Water \\
10 & 0.025 & 0.003 & $1.21 \times 106$ & $1.63 \times 104$ \\
200 & 0.49 & 0.06 & $2.41 \times 107$ & $3.27 \times 104$ \\
400 & 0.99 & 0.11 & $4.82 \times 107$ & $4.08 \times 104$ \\
500 & 1.24 & 0.14 & $6.03 \times 107$ & $5.72 \times 104$ \\
\hline 00 & 1.73 & 0.20 & $8.44 \times 107$ & \\
\hline
\end{tabular}

11. Wang $Q$, Yang L, Yang $X$, Wang $K$, He L, Zhu J. Electrochemical biosensors for detection of point mutation based on surface ligation reaction and oligonucleotides modified gold nanoparticles. Anal Chim Acta. 2011;688(2):163-7. PMID: 21334481. Available from: 10.1016/j.aca.2011.01.004.

12. Xie HJ, Lei QF, Fang WJ. Intermolecular interactions between gold clusters and selected amino acids cysteine and glycine: a DFT study. J Mol Model. 2012;18(2):645-52. PMID: 21562822. Available from: 10.1007/s00894-011-1112-6.

13. Srivastava R. Interaction of cysteine with Aun ( $n=8,10$, 12) even neutral clusters: $A$ theoretical study. Chem Select. 2017;2:2789-96.

14. Rai S, Kumar NV, Singh H. A theoretical study on interaction of proline with gold cluster. Bull Mater Sci. 2012;35(3):291-5. Available from: 10.1007/s12034-012-0314-6.

15. Pakiari $A H$, Jamshidi $Z$. Interaction of amino acids with gold and silver clusters. J Phys Chem A. 2007;111(20):4391-6. PMID: 17447742. Available from: 10.1021/jp070306t.

16. Javan MJ, Jamshidi Z, Tehrani ZA, Fattahi A. Interactions of coinage metal clusters with histidine and their effects on histidine acidity; theoretical investigation. Org Biomol Chem. 2012;10(47):9373-82. PMID: 23108513. Available from: 10. 1039/c2ob25711d.

17. Wang Y, Chi QJ, Hush NS, Reimers JR, Zhang JD, Ulstrup J. Scanning tunneling microscopic observation of adatommediated motifs on gold-thiolself-assembled monolayers at high coverage. J Chem Phys C. 2009;113(45):19601-8. Available from: 10.1021/jp906216k.

18. Feng J, Pandey RB, Berry RJ, Farmer BL, Naik RR, Heinz $\mathrm{H}$. Adsorption mechanism of single amino acid and surfactant molecules to $\mathrm{Au}(111)$ surfaces in aqueous solution: design rules for metal-binding molecules. Soft Matter. 2011;7(5):2113-20. Available from: 10.1039/c0sm01118e.

19. Ravindran A, Chandrasekaran N, Mukherjee A. Studies on differential behavior of silver nanoparticles towards thiol containing amino acids. Curr Nanosci. 2012;8(1):141-9. Available from: $10.2174 / 157341312799362331$.

20. Höffling B, Ortmann F, Hannewald K, Bechstedt F. Single cysteine adsorption on $\mathrm{Au}(110)$ : A first-principles study. Phys Rev B Condens Matter Mater Phys. 2010;81(4):045407. Available from: 10.1103/PhysRevB.81.045407.

21. Tehrani ZA, Jamshidi Z, Javan MJ, Fattahi A. Interactions of glutathione tripeptide with gold cluster: influence of intramolecular hydrogen bond on complexation behavior. J Phys Chem A. 2012;116(17):4338-47. PMID: 22356446. Available from: $10.1021 /$ jp2080226.

22. Sudeep PK, Joseph ST, Thomas KG. Selective detection of cysteine and glutathione using gold nanorods. J Am Chem Soc. 2005;127(18):6516-7. PMID: 15869256. Available from: $10.1021 / \mathrm{ja} 051145 \mathrm{e}$.

23. Frisch MJ, Trucks GW, Schlegel HB, Scuseria GE, Robb MA, Cheeseman JR. Gaussian 09 Revision: B.01. Wallingford (CT): Gaussian, Inc.; 2009.

24. Peterson KA, Puzzarini C. Systematically convergent basis sets for transition metals. II. Pseudopotential-based correlation consistent basis sets for the group $11(\mathrm{Cu}, \mathrm{Ag}, \mathrm{Au})$ and 12 (Zn, Cd, Hg) elements. Theor Chem Acc. 2005;114(4-5):28396. Available from: 10.1007/s00214-005-0681-9.

25. Tomasi J, Mennucci B, Cammi R. Quantum mechanical continuum solvation models. Chem Rev. 2005;105(8):2999-3093. PMID: 16092826. Available from: 10.1021/cr9904009.

26. Peyghan AA, Hadipour NL, Soleymanabadi $H$. Theoretical study on the Al-Doped $\mathrm{ZnO}$ nanoclusters for $\mathrm{CO}$ chemical sensors. J Phys Chem C. 2015;119(11):6398-404. Available from: $10.1021 /$ jp513019z.

27. O'Boyle NM, Tenderholt AL, Langner KM. cclib: a library for package-independent computational chemistry algorithms. J Comput Chem. 2008;29(5):839-45. PMID: 17849392. Available from: $10.1002 /$ jcc.20823.

28. Pearson RG. Hard and Soft Acids and Bases. J Am Chem Soc. 1963;85(22):3533-9. Available from: 10.1021/ja00905a001. 
29. Zhao Y, Zhou F, Zhou H, Su H. The structural and bonding evolution in cysteine-gold cluster complexes. Phys Chem Chem Phys. 2013;15(5):1690-8. PMID: 23247849. Available from: 10.1039/C2CP42830J.
30. Hosseinian A, Vessally E, Bekhradnia A, Ahmadi S, Nezhad PD. Interaction of $\alpha$-cyano-4-hydroxycinnamic acid drug with inorganic BN nanocluster: A density functional study. J Inorg Organomet Polym Mater. 2018;28(4):1422-31. Available from: 10.1007/s10904-018-0778-y. 